\title{
Mobilidade do Ametryn em Solos da Região SemiáRida do Rio GRANDE DO NORTE ${ }^{1}$
}

\author{
Ametryn Mobility in Soils of Rio Grande do Norte Semiarid Region \\ FREITAS, F.C.L. ${ }^{2}$, SILVA, A.A. ${ }^{3}$, SILVA, L.O.C. ${ }^{4}$, ROCHA; P.R.R. ${ }^{5}$, GUIMARÃES, F.C.N. ${ }^{6}$,
} FREITAS, M.A.M. ${ }^{7}$ e FELIPE, R. S. ${ }^{6}$

\begin{abstract}
RESUMO - Objetivou-se com este trabalho avaliar o potencial de mobilidade do ametryn em quatro tipos de solos: três da região semiárida do Estado do Rio Grande do Norte (Cambissolo, Neossolo Flúvico e Argissolo Vermelho-Amarelo distrófico latossólico) e um do Estado de Minas Gerais (Latossolo Vermelho-Amarelo). A avaliação da mobilidade do ametryn foi feita utilizando colunas de PVC de $10 \mathrm{~cm}$ de diâmetro e $50 \mathrm{~cm}$ de comprimento. O experimento foi conduzido no esquema de parcelas subdivididas, no delineamento inteiramente casualizado com quatro repetições. As parcelas foram compostas pelas colunas, preenchidas com os quatro tipos de solo, e as subparcelas, por 10 profundidades com intervalos de $5 \mathrm{~cm}(0-5$, 5-10, 10-15, 15-20, 20-25, 25-30, 30-35, 35-40, 40-45 e 45-50 cm). No topo das colunas, realizouse aplicação de ametryn $(4 \mathrm{~kg} \mathrm{ha-1)}$ e, 12 horas após, simulou-se chuva de $60 \mathrm{~mm}$. Após 72 horas da simulação da chuva, as colunas foram colocadas na posição horizontal e abertas longitudinalmente, divididas em seções de $5,0 \mathrm{~cm}$. No centro de cada seção das colunas, foram coletadas amostras de solo para posterior extração e quantificação do herbicida através de análise por cromatografia liquida de alta eficiência (CLAE). Após a coleta das amostras para extração, procedeu-se à semeadura de cinco sementes de pepino (Cucumis sativus) como planta indicadora da presença do herbicida. A mobilidade do ametryn nas colunas foi influenciada pelas características físicas e quimicas do solo, como textura, teor de argila e de matéria orgânica e pH. Os solos da região semiárida do Rio Grande do Norte apresentaram maior potencial de mobilidade do ametryn, sendo detectado até 25, 20 e $15 \mathrm{~cm}$ de profundidade no Argissolo Vermelho-Amarelo distrófico latossólico, Cambissolo e Neossolo flúvico, respectivamente. No Latossolo Vermelho-Amarelo, com maior teor de matéria orgânica e pH 4,7, a mobilidade do ametryn restringiu-se a $5 \mathrm{~cm}$ de profundidade. O método do bioensaio com pepino como planta indicadora pode ser utilizado em estudos de lixiviação desse herbicida, em substituição ao método cromatográfico.
\end{abstract}

Palavras-chave: matéria orgânica, lixiviação de herbicida, bioensaio, cromatografia.

\begin{abstract}
This work aimed to evaluate ametryn mobility in four types of soils, three from the semiarid region of the state of Rio Grande do Norte (Cambisol; Fluvic Neosol; Latosolic Dystrophic Red-Yellow Argisol) and one from the state of Minas Gerais (Red-Yellow Latosol). Ametryn mobility was evaluated using PVC columns of $10 \mathrm{~cm}$ in diameter and $50 \mathrm{~cm}$ long. The experiment was conducted in a split-plot in a completely randomized design with four replications. The plots were composed by the columns, filled with the four types of soils and the subplots by 10 depths at intervals of $5 \mathrm{~cm}(0-5,5-10,10-15,15-20,20-25,25-30,30-35,35-40,40-45$ and $45-50 \mathrm{~cm})$. Ametryn was applied on top of the columns (4 $\left.\mathrm{kg} \mathrm{ha}^{-1}\right)$ and, 12 hours later, rainfall was simulated at the intensity of $60 \mathrm{~mm}$. After 72 hours of simulated rain, the columns were placed in a horizontal position and opened longitudinally, divided into sections of $5.0 \mathrm{~cm}$. At the center of each section,
\end{abstract}

1 Recebido para publicação em 14.9.2011 e aprovado em 24.6.2012.

2 Professor Adjunto, Dep. de Ciências Vegetais, Universidade Federal Rural do Semi-Árido - UFERSA, <fclaudiof@yahoo.com.br>; ${ }^{3}$ Professor Associado, Dep. de Fitotecnia, Universidade Federal de Viçosa, DFT/UFV, <aasilva@ufv.brr>; ${ }^{4}$ Professora, Instituto Federal de Educação Ciência e Tecnologia do Sudeste de Minas -IFSUDESTEMG, Campus Barbacena, <leandra_cruz@yahoo.com.br>; ${ }^{5}$ Bolsista PNPD-UFERSA < pauloagro01@yahoo.com.br>; ${ }^{6}$ Estudante de graduação do curso de Agronomia - UFV; ${ }^{7}$ Doutorando em Fitotecnia, DFT/UFV.

Planta Daninha, Viçosa-MG, v. 30,n. 3, p. 641-648, 2012 
soil samples were collected for subsequent herbicide extraction and quantification through analysis by liquid chromatography (HPLC). Five seeds of cucumber (Cucumis sativus) were sown as bio-indicators of the presence of the herbicide. Ametryn mobility at the columns was influenced by the physical and chemical characteristics of the soil,(soil texture, organic matter, and pH). The Rio Grande do Norte semiarid region soils had higher ametryn mobility potential, being detected at up to 25, 20, and $15 \mathrm{~cm}$ depth in Latosolic Dystrophic Red-Yellow Argisol, Cambisol, and Fluvic Neosol, respectively. Ametryn mobility was restricted to $5 \mathrm{~cm}$ depth in the Red Yellow Latosol, with higher organic matter content and pH 4.7. The bioassay method was more efficient to confirm ametryn leaching than liquid chromatography.

Keywords: organic matter, herbicide leaching, bioassay, chromatography.

\section{INTRODUÇÃO}

O Brasil é um dos maiores produtores de alimentos, fibras e biocombustiveis do mundo, o que se deve à grande área cultivada e à elevação da produtividade em culturas como soja, cana-de-açúcar, milho e algodão. A produção nacional de grãos para a safra 2010/11 está estimada em 161,5 milhões de toneladas aumento de $8,2 \%$ ou cerca de 12,2 milhões de toneladas a mais que a safra passada, que foi de 149,2 milhões de toneladas. Em relação à safra 2001/02, o aumento foi de 64,19\%, com incremento de $12,3 \%$ na área cultivada. A área cultivada com a cana-de-açúcar colhida destinada à atividade sucroalcooleira está estimada em 8,4 milhões de hectares - aumento de 49,8\% em relação à safra 2004/05 (CONAB, 2011). Todavia, diante da redução da disponibilidade de mão de obra no campo, o cultivo de áreas extensas somente está sendo possivel graças ao avanço tecnológico, como o uso de herbicidas para controle de plantas daninhas.

No entanto, é fundamental que os herbicidas sejam adequadamente utilizados no sentido de preservar não só a qualidade do produto final colhido, mas também os próprios recursos naturais finitos que sustentam a produção, especialmente o solo e a água. Alguns herbicidas, especialmente os que apresentam longo período residual em solos, podem causar problemas ambientais, como a contaminação do solo, da água e da microbiota do solo (Inoue et al., 2002). A dinâmica de um herbicida no ambiente e o seu efeito residual no solo são condicionados às propriedades físico-químicas do produto utilizado, às condições climáticas no momento da aplicação e no decorrer da persistência do herbicida no solo e às características edáficas, entre outros fatores. O conhecimento desses fatores é de fundamental importância para prever o comportamento de herbicidas nas diferentes classes de solo e para seleção de dosagens adequadas, bem como para evitar efeitos prejudiciais ao ambiente e às culturas subsequentes (Monquero et al., 2010).

Esses compostos têm sido detectados em estudos de qualidade de águas superficiais e subterrâneas (Carter, 2000; Tanabe et al., 2001). Monteiro et al. (2008) comprovaram a contaminação de cursos d'água por ametryn, atrazine e simazine no Estado de São Paulo, em regiões com intenso cultivo de cana-deaçúcar.

$\mathrm{O}$ ametryn é um dos principais herbicidas utilizados na cultura da cana-de-açúcar; nos últimos anos, diversos estudos têm sido realizados no sentido de melhor entender o comportamento desse composto nos solos brasileiros (Prata et al., 2001; Vivian et al., 2007; Silva, 2009; Andrade et al., 2010a, b). Tem sido demonstrado que a dinâmica do ametryn é muito dependente das características físicas e químicas do solo, com destaque para o teor de matéria orgânica, o pH e a textura. Contudo, no que se refere aos solos da região semiárida do Nordeste brasileiro, cujas características físicas e químicas são bastante distintas das dos solos das regiões tropicais do País, esses estudos são escassos.

Objetivou-se com este trabalho avaliar a mobilidade do ametryn em solos da região semiárida do Estado do Rio Grande do Norte com diferentes características físico-químicas e em solo da Zona da Mata de Minas Gerais, para efeito de comparação. 


\section{MATERIAL E MÉTODOS}

Para realização deste trabalho foram utilizadas amostras de quatro tipos de solo, coletadas na profundidade de 0 a $20 \mathrm{~cm}$ em áreas sem histórico de aplicação de ametryn, sendo três da região semiárida do Estado Rio Grande do Norte: Cambissolo no municipio de Apodi-RN, Neossolo Flúvico no município de Ipanguaçu-RN e Argissolo Vermelho-Amarelo distrófico latossólico no município de MossoróRN; e um da Zona da Mata de Minas Gerais: Latossolo Vermelho-Amarelo, no município de Viçosa-MG.

As amostras dos solos foram secas ao ar, destorroadas e passadas em peneiras com malha de $4 \mathrm{~mm}$. De cada amostra de solo foi retirada uma subamostra, para realização de análises química e física (Tabela 1), segundo metodologia descrita pela Embrapa (1997).
Os solos foram acondicionados em colunas de PVC de $10 \mathrm{~cm}$ de diâmetro por $50 \mathrm{~cm}$ de comprimento, previamente preparadas e parafinadas no seu interior, para evitar escorrimento lateral da água. Todas as colunas foram marcadas e seccionadas a cada $5 \mathrm{~cm}$ de distância com tampa lateral removivel (Figura 1). Após o preenchimento com os solos estudados, elas foram saturadas com água, por um período de 48 horas. Posteriormente, as colunas foram deixadas na posição vertical, em repouso, por 72 horas, visando drenar o excesso de água, conforme Andrade et al. (2010b).

Em seguida, foi feita a aplicação do herbicida ametryn no topo das colunas, na dose de $4 \mathrm{~kg} \mathrm{ha}{ }^{-1}$. Doze horas após a aplicação do herbicida, estando as colunas ainda na posição vertical, procedeu-se à simulação da chuva, com a aplicação de lâmina única de $60 \mathrm{~mm}$,

Tabela 1 - Resultados das análises química e física das amostras dos solos: Cambissolo (CB), Neossolo Flúvico (NF), Argissolo Vermelho-Amarelo distrófico latossólico (AVA) e Latossolo Vermelho-Amarelo (LVA)

\begin{tabular}{|c|c|c|c|c|c|c|c|c|c|c|c|c|c|c|}
\hline \multicolumn{15}{|c|}{ Análise química } \\
\hline \multirow{2}{*}{ Solo } & $\mathrm{pH}$ & $\mathrm{P}$ & $\mathrm{K}$ & $\mathrm{Ca}$ & $\mathrm{Mg}$ & $\mathrm{Al}$ & $\mathrm{H}+\mathrm{Al}$ & SB & (t) & $(\mathrm{T})$ & V & $\mathrm{m}$ & $\mathrm{MO}$ & P-rem \\
\hline & $\left(\mathrm{H}_{2} \mathrm{O}\right)$ & \multicolumn{2}{|c|}{$\left(\mathrm{mg} \mathrm{dm}^{-3}\right)$} & \multicolumn{7}{|c|}{$\left(\mathrm{cmol}_{\mathrm{c}} \mathrm{dm}^{-3}\right)$} & \multicolumn{2}{|c|}{$(\%)$} & $\left(\right.$ dag kg $\left.^{-1}\right)$ & $\left(\mathrm{mg} \mathrm{L}^{-1}\right)$ \\
\hline $\mathrm{CB}$ & 6,8 & 3,3 & 177 & 3,3 & 0,9 & 0,0 & 1,49 & 4,55 & 4,55 & 6,04 & 75 & 0 & 1,2 & 29,5 \\
\hline $\mathrm{NF}$ & 7,2 & 76,9 & 220 & 4,6 & 2,2 & 0,0 & 0,17 & 7,36 & 7,46 & 7,53 & 98 & 0 & 1,0 & 44,5 \\
\hline AVA & 4,9 & 1,0 & 10 & 0,1 & 0,0 & 0,2 & 0,50 & 0,13 & 0,33 & 0,63 & 21 & 61 & 0,1 & 53,0 \\
\hline LVA & 4,7 & 2,1 & 25 & 0,4 & 0,1 & 1,8 & 9,90 & 0,56 & 2,36 & 10,46 & 5 & 76 & 3,3 & 20,3 \\
\hline \multicolumn{15}{|c|}{ Análise física } \\
\hline \multirow{2}{*}{\multicolumn{2}{|c|}{ Solo }} & \multicolumn{2}{|c|}{ A. Grossa } & \multicolumn{3}{|c|}{ A. Fina } & \multicolumn{2}{|c|}{ Silte } & \multicolumn{2}{|c|}{ Argila } & & \multirow{2}{*}{\multicolumn{3}{|c|}{ Classe Textural }} \\
\hline & & \multicolumn{9}{|c|}{$\left(\right.$ dag kg $\left.{ }^{-1}\right)$} & & & & \\
\hline \multicolumn{2}{|c|}{$\mathrm{CB}$} & \multicolumn{2}{|c|}{60} & \multicolumn{3}{|c|}{15} & \multicolumn{2}{|c|}{6} & \multicolumn{2}{|c|}{17} & \multirow{2}{*}{\multicolumn{4}{|c|}{ Franco-arenosa }} \\
\hline \multicolumn{2}{|c|}{ NF } & \multicolumn{2}{|c|}{9} & \multicolumn{3}{|c|}{56} & \multicolumn{2}{|c|}{26} & \multicolumn{2}{|c|}{9} & & & & \\
\hline \multicolumn{2}{|c|}{ AVA } & \multicolumn{2}{|c|}{80} & \multicolumn{3}{|c|}{11} & \multicolumn{2}{|c|}{4} & \multicolumn{2}{|c|}{5} & \multicolumn{4}{|c|}{ Areia } \\
\hline \multicolumn{2}{|c|}{ LVA } & \multicolumn{2}{|c|}{27} & \multicolumn{3}{|c|}{14} & 6 & & 5 & & & & Argiloso & \\
\hline
\end{tabular}
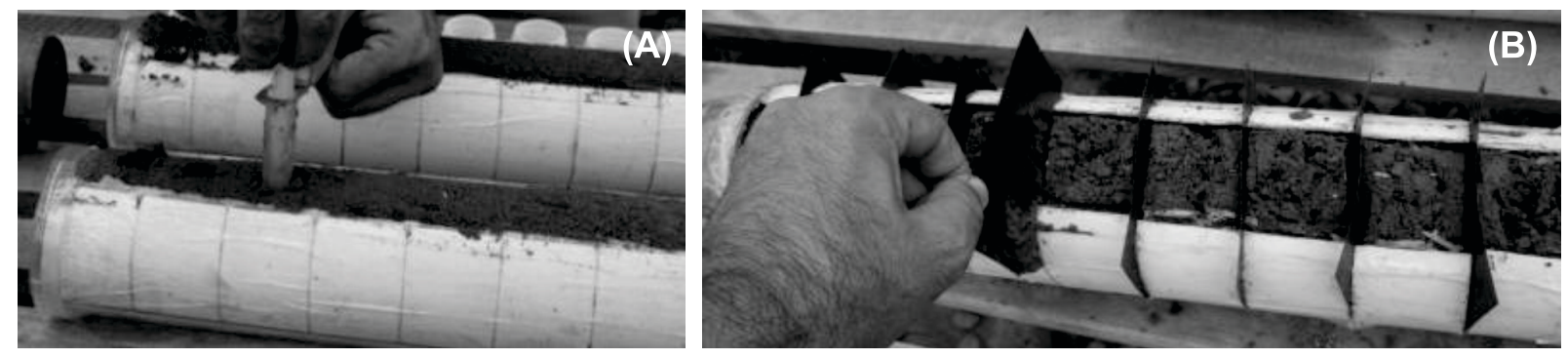

Figura 1 - Coleta de amostra de solo para análise por cromatografia líquida em colunas abertas lateralmente (A) e seccionamento a cada $5 \mathrm{~cm}$ com lâmina de PVC (B) 
no intervalo de três horas, para o Cambissolo, Argissolo Vermelho-Amarelo distrófico latossólico e Latossolo Vermelho-Amarelo. No entanto, para o Neossolo Flúvico, foram necessárias 24 horas, devido à menor velocidade de infiltração de água.

Após 72 horas na posição vertical, as colunas foram colocadas na posição horizontal, quando foi feita a abertura lateral e o seccionamento a cada $5 \mathrm{~cm}$ com lâmina de PVC (Figura 1A).

No centro de cada seção das colunas, foram coletadas amostras de solo (Figura 1B), que foram secas ao ar, destorroadas e congeladas em temperatura de aproximadamente $-20{ }^{\circ} \mathrm{C}$, para posterior extração e quantificação do herbicida no solo por análise cromatográfica. Após a coleta das amostras para extração, procedeu-se à semeadura de cinco sementes de pepino (Cucumis sativus) por segmento da coluna, como planta indicadora da presença do ametryn. O bioensaio foi conduzido em casa de vegetação durante 14 dias após a emergência. Para manutenção do teor de água, foram feitas irrigações diárias, repondose a água evapotranspirada. Além das irrigações, as plantas foram tratadas com solução de complementação nutricional.

Aos 14 dias após a emergência (DAE) da espécie indicadora, foi realizada a avaliação da mobilidade do herbicida pelo método indireto (biológico), avaliando-se o indice de intoxicação e o acúmulo de matéria seca das plantas. $\mathrm{Na}$ avaliação do índice de intoxicação das plantas indicadoras foram atribuídas notas de 0 (ausência de intoxicação) a 100 (morte da planta). Na avaliação da matéria seca, todas as plantas foram cortadas rente à superficie do solo e colocadas em estufa de circulação forçada de ar $\left(70 \pm 2{ }^{\circ} \mathrm{C}\right)$ até peso constante.

Para extração do ametryn das amostras de solo foi utilizada a técnica de extração sólidolíquido, com partição em baixa temperatura, proposta por Vieira et al. (2007), Goulart et al. (2008) e Andrade et al. (2010a).

O processo consistiu em medir uma massa de 2,00 g de solo seco, previamente homogeneizado e quarteado, em frascos de vidro de tampa rosqueável com $22,0 \mathrm{~mL}$ de capacidade; adicionaram-se a seguir $12,0 \mathrm{~mL}$ da mistura extratora, composta por 4,0 mL de água, $6,5 \mathrm{~mL}$ de acetonitrila e $1,5 \mathrm{~mL}$ de acetato de etila. Os frascos foram submetidos a agitação vertical durante 30 minutos. Posteriormente, as amostras foram deixadas por \pm 12 horas em freezer em temperatura de aproximadamente $-20{ }^{\circ} \mathrm{C}$. Após esse período, fez-se a filtração da fração não congelada, extrato orgânico e herbicida, para balão volumétrico de $10,0 \mathrm{~mL}$. As frações que continham solo e água congelada foram descartadas. Após atingir a temperatura ambiente, as soluções filtradas foram transferidas para um balão de fundo redondo com $10,0 \mathrm{~mL}$ de capacidade, para evaporação dos solventes em evaporador rotatório, em temperatura de $50 \pm 1{ }^{\circ} \mathrm{C}$. Após a evaporação, o balão de fundo redondo foi lavado com três alíquotas de $0,50 \mathrm{~mL}$ de acetonitrila, e o extrato final, novamente filtrado em membrana de $0,45 \mu \mathrm{m}$ e armazenado em vials de $1,5 \mathrm{~mL}$ de capacidade.

A detecção e quantificação do ametryn foi realizada utilizando-se um sistema de cromatografia líquida de alta eficiência, modelo Shimadzu LC 20AT, com detector UV-Vis (Shimadzu SPD 20A), coluna de aço inox (Shimadzu VP- ODS Shim-pack $150 \mathrm{~mm}$ x 4,6 mm d.i.) As condições cromatográficas para a análise foram: fase móvel: água e acetonitrila na proporção $70: 30(\mathrm{v} / \mathrm{v})$, respectivamente, e acidificada com $0,02 \%$ de ácido fosfórico,

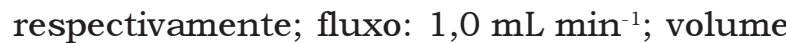
de injeção: $20 \mu \mathrm{L}$; temperatura da coluna: $30{ }^{\circ} \mathrm{C}$; comprimento de onda: $245 \mathrm{~nm}$; e tempo de retenção de aproximadamente 5,5 minutos.

A solução-estoque do herbicida foi preparada a partir do padrão com $98,3 \%$ de pureza, na concentração de $1.000 \mu \mathrm{g} \mathrm{mL}^{-1} \mathrm{em}$ acetonitrila, e as soluções de trabalho, preparadas a partir desta, em triplicata. A quantificação foi feita por meio da comparação das áreas obtidas nos cromatogramas pelo método de calibração externa.

O experimento foi conduzido no campus da Universidade Federal de Viçosa, em ViçosaMG, no esquema de parcelas subdivididas, no delineamento inteiramente casualizado com quatro repetições. As parcelas foram compostas pelas colunas preenchidas com os quatro tipos de solo, e as subparcelas, por 10 profundidades, com intervalos de $5 \mathrm{~cm}(0-5,5-10$, 
$10-15,15-20,20-25,25-30,30-35,35-40,40-45$ e $45-50 \mathrm{~cm})$.

Para interpretação dos resultados, os dados obtidos no bioensaio e na análise cromatográfica foram submetidos à análise de variância e de regressão. Na escolha dos modelos foram levados em consideração a resposta biológica, a significância dos coeficientes de regressão e os coeficientes de determinação.

\section{RESULTADOS E DISCUSSÃO}

O potencial de lixiviação do ametryn foi influenciado pelas características físicoquímicas dos solos, evidenciada pela variação nos valores do índice de intoxicação visual na planta indicadora, observados nas Figuras 2 e 3 , onde se verifica que o herbicida causou a morte das plantas em todos os solos no primeiro segmento, até $5 \mathrm{~cm}$ de profundidade. No segundo segmento, $5-10 \mathrm{~cm}$ de profundidade, o herbicida foi detectado em todos os solos, com exceção do Latossolo Vermelho-Amarelo (LVA). Essa baixa mobilidade deve-se principalmente

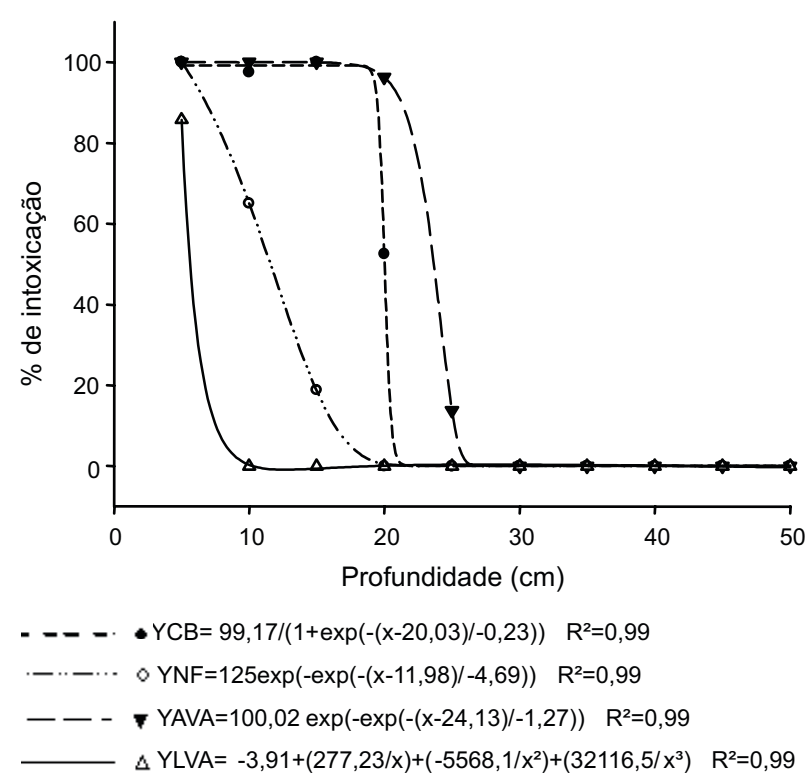

Figura 2 - Porcentagem de intoxicação nas plantas de pepino em diferentes profundidades das colunas, nos quatro solos: Cambissolo (CB), Neossolo Flúvico (NF), Argissolo Vermelho-Amarelo distrófico latossólico (AVA) e Latossolo Vermelho-Amarelo (LVA), após a aplicação de ametryn e simulação de chuva de $60 \mathrm{~mm}$. Viçosa-MG, 2009. ao maior teor de matéria orgânica $(3,3 \%)$, a textura argilosa. Além do maior teor de matéria orgânica, o pH do LVA $(4,7)$, mais próximo do pKa do ametryn $(4,1)$, favorece a adsorção do herbicida pelos coloides do solo, que apresenta predominantemente cargas negativas (Lindsay, 2001), dificultando sua lixiviação. Para Oliveira Jr. et al. (2001), o teor de matéria orgânica é o fator mais determinante na adsorção do ametryn. Andrade et al. (2010a) constataram que o baixo teor de matéria orgânica e/ou $\mathrm{pH}$ mais elevado diminuíram a sorção do ametryn, disponibilizando maior quantidade do herbicida na solução do solo, favorecendo assim sua mobilidade no perfil deste.

No terceiro segmento, 10 a $15 \mathrm{~cm}$ de profundidade, o herbicida foi detectado nos três solos da região semiárida do Rio Grande do Norte, porém com sintomas menos pronunciados no Neossolo Flúvico (NF). Essa menor mobilidade pode ter sido influenciada, entre outros fatores, pela dificuldade de infiltração de água nesse solo, conforme verificado por ocasião da simulação da chuva, o que pode ter dificultado a movimentação do herbicida no perfil, funcionando como uma espécie de filtro. Para Prata et al. (2003), a composição, o tamanho e a distribuição das partículas do solo e sua respectiva porosidade influenciam no movimento descendente dos herbicidas.

O ametryn foi detectado entre 15 e $20 \mathrm{~cm}$ de profundidade pela planta indicadora no Argissolo Vermelho-Amarelo distrófico latossólico (AVA) e no Cambissolo, embora com sintomas menos pronunciados neste último. No entanto, entre 20 e $25 \mathrm{~cm}$ de profundidade, o composto causou intoxicação apenas em plantas de pepino no AVA, o que se deve, provavelmente, à textura arenosa (91\% de areia), que facilita a movimentação da água na matriz, associada ao baixo teor de matéria orgânica $(0,1 \%)$.

Andrade et al. (2010b) verificaram maior mobilidade de ametryn em solos com baixo teor de matéria orgânica. Segundo Vivian et al. (2007) e Tavares et al. (2005), o ametryn é uma base fraca e tem suas moléculas atraídas eletrostaticamente pelos grupos carboxílicos, fenólicos, entre outros a matéria orgânica, o que o deixa menos disponivel na solução do solo. Silva (2009) verificou que, além do teor 

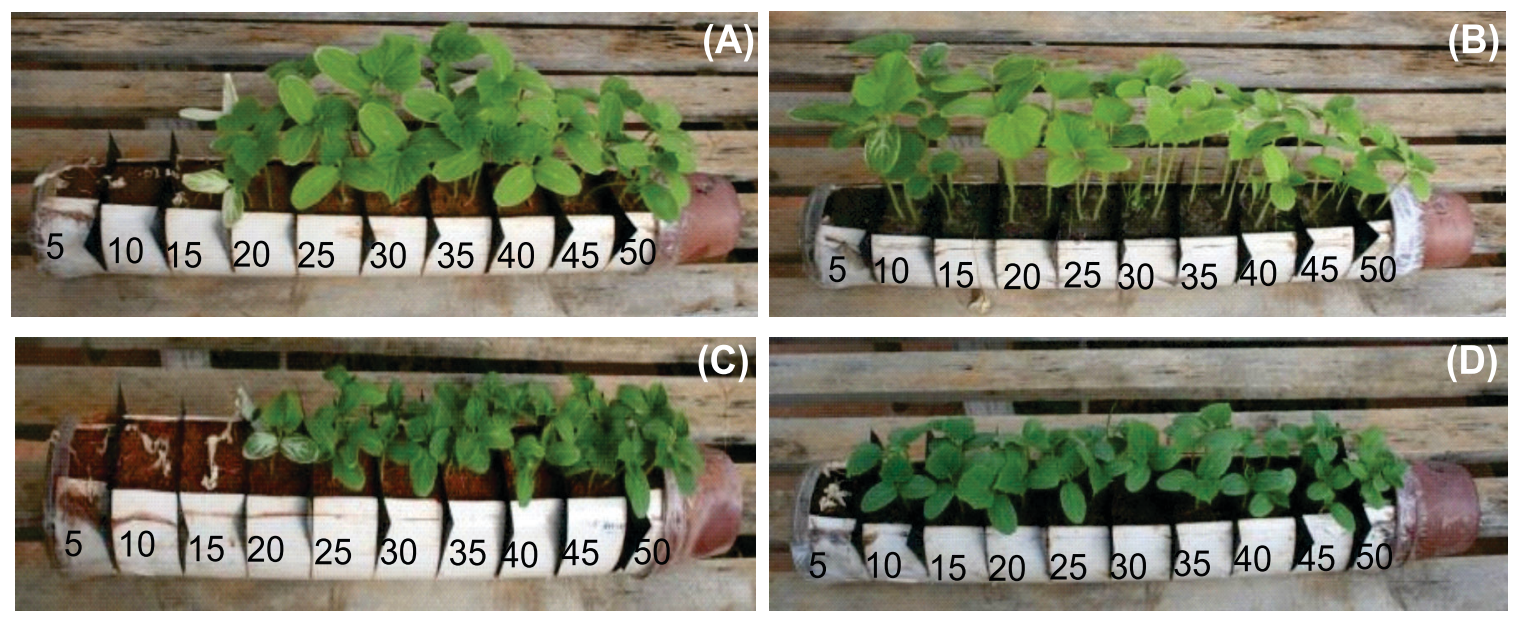

Figura 3 - Sintomas visuais de intoxicação de ametryn em plantas de pepino, aos 14 dias após a semeadura, em diferentes profundidades das colunas (cm), nos quatro solos: Cambissolo (Foto A), Neossolo Flúvico (Foto B), Argissolo Vermelho-Amarelo distrófico latossólico (Foto C) e Latossolo Vermelho-Amarelo (Foto D). Viçosa-MG, 2009

de matéria orgânica, as características físicas do solo, como o teor de argila, também podem ser um importante fator na mobilidade desse herbicida.

O Cambissolo e o Neossolo Flúvico, provavelmente, tiveram a mobilidade do herbicida favorecida pelas suas características químicas (Tabela 1), pois apresentam $\mathrm{pH}$ elevado $(6,8 \mathrm{e}$ 7,2 , respectivamente), bastante distantes do pKa do ametryn $(4,1)$, além do teor de matéria orgânica relativamente baixo $(1,2$ e 1,0 , respectivamente), favorecendo assim a permanência do herbicida na solução do solo; consequentemente, houve lixiviação do ametryn nesses solos.

Em condições em que o pH do solo está próximo ao valor do $\mathrm{pKa}$ dos herbicidas básicos, como o ametryn, pode ocorrer a protonação das moléculas, assumindo cargas positivas (Ferri et al., 2000). Essas cargas podem promover a adsorção do ametryn aos coloides do solo, que apresentam predominantemente cargas negativas (Lindsay, 2001). Segundo Andrade et al. (2010b), em solos com baixo teor de matéria orgânica fica mais evidente a influência do $\mathrm{pH}$ na distribuição das cargas e, consequentemente, sobre o potencial de lixiviação dos herbicidas.

O acúmulo de massa da matéria seca pela planta indicadora (Figura 4) apresentou menor sensibilidade que a avaliação visual de intoxicação (Figura 2), visto que a planta pode apresentar sintomas de intoxicação do herbicida sem afetar sua taxa de crescimento (Velini et al., 2008; Silva et al., 2009). Além disso, subdoses de herbicidas podem influenciar positivamente o crescimento em altura e o acúmulo de massa da matéria seca das plantas (Velini et al., 2008; Silva et al., 2009), tornando essa variável imprecisa em determinadas situações. $O$ fato mencionado pode ser verificado nas Figuras 3B e 4, no Neossolo Flúvico, onde se observam sintomas evidentes do herbicida intoxicando a planta, coincidindo com o incremento no acúmulo de massa da matéria seca e posterior declínio, quando desaparecem os sintomas do ametryn.

A detecção do ametryn através do método cromatográfico foi inferior à avaliação visual de intoxicação no bioensaio (Figuras 2 e 5), apresentando a vantagem de determinar a concentração do herbicida no perfil do solo. Conforme observado na Figura 4, percebe-se maior concentração do ametryn até $7,5 \mathrm{~cm}$ de profundidade e posterior declínio no AVA, enquanto no LVA a menor mobilidade do herbicida resultou em elevada concentração apenas no primeiro segmento. Andrade et al. (2010b) também verificaram que o método do bioensaio foi mais eficiente na confirmação da lixiviação desse herbicida, em comparação à técnica cromatográfica.

A cromatografia requer laboratórios sofisticados e mão de obra altamente qualificada e consome grande quantidade de solventes e 


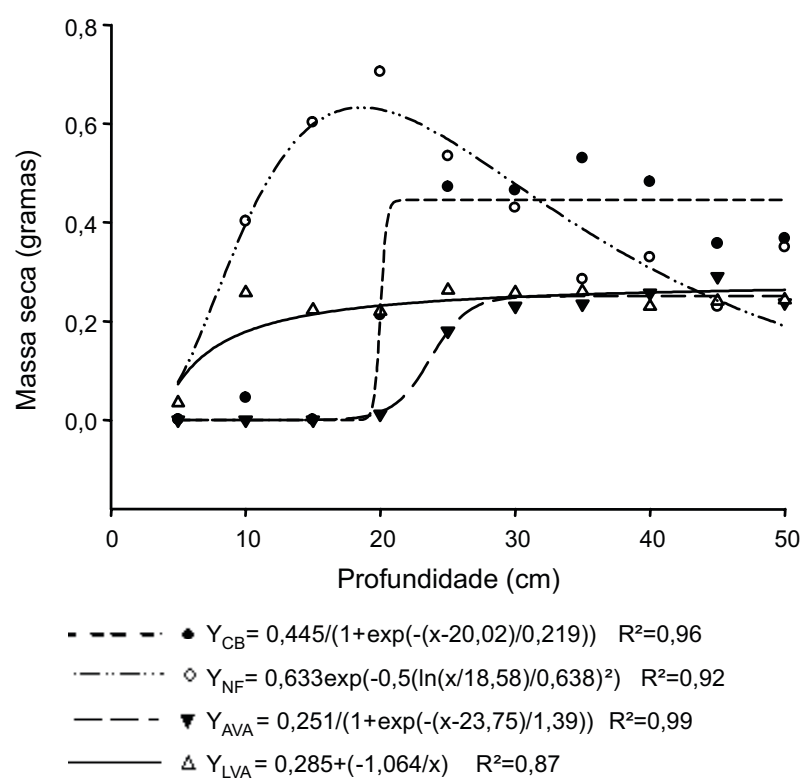

Figura 4 - Massa da matéria seca de pepino em diferentes profundidades das colunas, nos quatro solos: Cambissolo (CB), Neossolo Flúvico (NF), Argissolo Vermelho-Amarelo distrófico latossólico (AVA) e Latossolo vermelho-Amarelo (LVA), após a aplicação de ametryn e simulação de chuva de 60 mm. Viçosa-MG, 2009

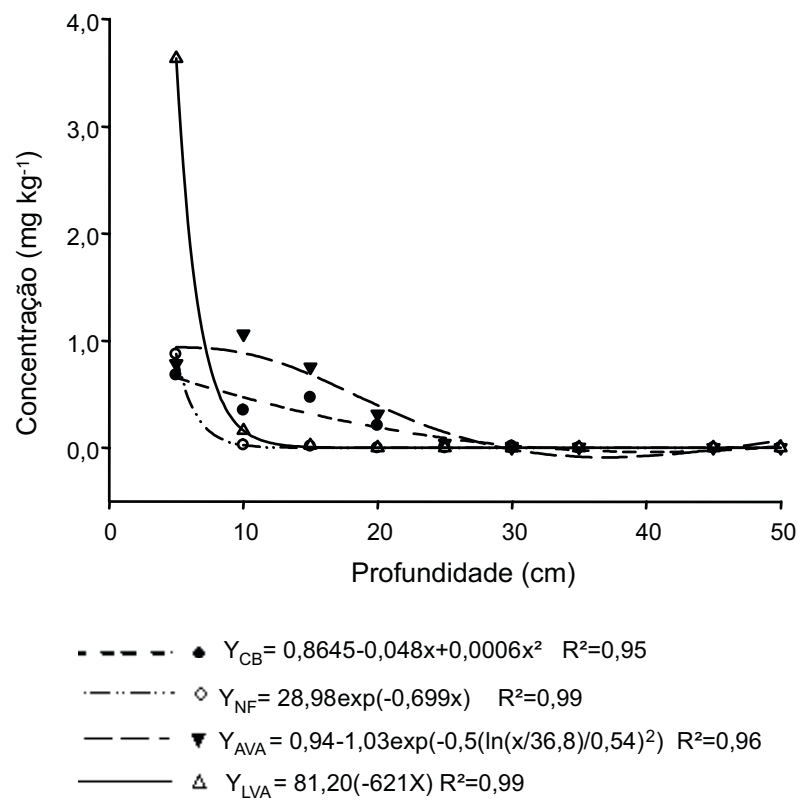

Figura 5 - Concentrações de ametryn em diferentes profundidades das colunas, nos quatro solos: Cambissolo (CB), Neossolo Flúvico (NF), Argissolo Vermelho-Amarelo distrófico latossólico (AVA) e Latossolo Vermelho-Amarelo (LVA), após a aplicação de ametryn e simulação de chuva de 60 mm. Viçosa-MG, 2009 outros produtos químicos, que podem contaminar o meio ambiente, ao passo que a detecção através do ensaio biológico é um processo muito mais simples e barato e não requerer estruturas, corroborando Melo et al. (2010), os quais afirmam que o bioensaio alia baixo custo ao bom resultado prático.

A mobilidade do herbicida no perfil do solo pode ser benéfica quando este exerce seu efeito sobre sementes ou plântulas durante a germinação ou emergência; contudo, quando excessiva, como é o caso do AVA neste trabalho, pode acarretar redução da eficácia pela percolação do composto no perfil do solo, além da possibilidade de contaminação do lençol freático.

Conclui-se que os solos da região semiárida do Rio Grande do Norte apresentam maior potencial de mobilidade do ametryn em relação ao Latossolo Vermelho-Amarelo de Minas Gerais, sendo esta influenciada pelas características físicas e químicas do solo, como textura, teor de argila, matéria orgânica e pH. O método do bioensaio com pepino como planta indicadora foi mais eficiente na confirmação da lixiviação desse herbicida, em comparação com a técnica cromatográfica.

\section{LITERATURA CITADA}

ANDRADE, S. R. B. et al. Sorção e dessorção do ametryn em Argissolo Vermelho-Amarelo e Latossolo Vermelho-Amarelo com diferentes valores de $\mathrm{pH}$. Planta Daninha, v. 28, n. 1, p. 177-184, 2010a.

ANDRADE, S. R. B. et al. Lixiviação do ametryn em Argissolo Vermelho-Amarelo e Latossolo Vermelho-Amarelo, com diferentes valores de $\mathrm{pH}$. Planta Daninha, v. 28, n. 3, p. $655-663,2010$ b.

CARTER, A. D. Herbicide movement in soils: principles, pathways and processes. Weed Res., v. 40, n. 1, p. 113-122, 2000 .

COMPANHIA NACIONAL DE ABASTECIMENTO CONAB. Levantamentos de safra. Disponível em: $<$ http:// www. conab. gov.br/conteudos.php? $\mathrm{a}=1253 \& \mathrm{t}=\&$ Pagina objcmsconteudos=1\#A_objcmsconteudos $>$. Acesso em: 20 jun. 2011

EMPRESA BRASILEIRA DE PESQUISA AGROPECUÁRIA - EMBRAPA. Manual de métodos de análise de solo. 2.ed. Rio de Janeiro: 1997. 212 p.

Planta Daninha, Viçosa-MG, v. 30,n. 3, p. 641-648, 2012 
FERRI, M. V. W. et al. Atividade dos herbicidas flumetsulam e trifluralin em diferentes valores de $\mathrm{pH}$ e densidade do solo. Ci. Rural, v. 30, n. 1, p. 11-15, 2000

GOULART, S. M. et al. Low temperature clean-up method for the determination of pyrethroids in milk using gas chromatography with electron capture detection. Talanta, v. 75, n. 5 , p. $1320-1323,2008$.

INOUE, M. H. et al.. Calagem e o potencial de lixiviação de imazaquin em colunas de solo. Planta Daninha, v. 20, n. 1, p. $125-132,2002$.

LINDSAY, W. L. Chemical equilibria in soils. New Jersey: Blackburn, 2001. 449 p

MELO, C. A. D. et al. Lixiviação de sulfentrazone, isoxaflutole e oxyfluorfen no perfil de três solos

Planta Daninha, v. 28, n. 2, p. 385-392, 2010.

MONQUERO, P. A. et al. Lixiviação e persistência dos herbicidas sulfentrazone e imazapic. Planta Daninha, v. 28, n. 1, p. $185-195,2010$.

MONTEIRO, R. T. R. et al. Projeto Políticas Públicas. In TAUK-TORNISIELO, S. M.; ESQUIERRO, J. C. (Org.). Bacia do Rio Corumbataí: aspectos socioeconômicos e ambientais. Rio Claro: Biblioteca da Unesp - Campus de Rio Claro/SP, 2008. p. 5-178.

OLIVEIRA JR., R. S; KOSKINEN, W. C; FERREIRA, F. A. Sorption and leaching potential of herbicides in Brazilian soils. Weed Res., v. 41, n.2, p. 97-110, 2001.

PRATA, F. et al. Degradação e sorção de ametryn em dois solos com aplicação de vinhaça. Pesq. Agropec. Bras., v. 36, n. 7, p. 975-981, 2001.
PRATA, F. et al. Glyphosate sorption and desorption in soils with different phosphorous levels. Sci. Agric., v. 60, n. 1, p. $175-180,2003$.

SILVA, L. L. Sorção e mobilidade do ametryn em Latossolos com diferentes características físicas e químicas. 2009. 39 f. Dissertação (Mestrado em Solos e Nutrição de Plantas) - Universidade Federal de Viçosa, Viçosa, MG, 2009.

SILVA, M. A. et al. Efeito hormótico de gliphosate no desenvolvimento inicial de cana-de-açúcar.

Bragantia, v. 68, n. 4, p. 973-978, 2009.

TANABE, A. et al. Seasonal and special studies on pesticides residues in surface eaters of the Shinano river in Japan. J. Agric. Food Chem., v. 49, n. 7, p. 3847-3852, 2001.

TAVARES, A. et al. Determination of ametryn in soils via microwave-assisted solvent extraction coupled to anodic stripping voltammetry with a gold ultramicroelectrode. Anal. Bional. Chem., v. 382, n. 2, p. 477-484, 2005.

VELINI, E. D. et al. O. Glyphosate applied at low doses can stimulate plant growth. Pest Manag. Sci., v. 64, n.4, p. 48996, 2008 .

VIEIRA, H. P.; NEVES, A. A; QUEIROZ, M. E. L. R. Otimização e validação da técnica de extração líquido-líquido com partição em baixa temperatura (ELLPBT) para piretróides em água e análise por CG. Quim. Nova, v. 30, n. 3, p. 535-540, 2007.

VIVIAN, R. et al. Persistência e lixiviação de ametryn e trifloxysulfuron-sodium em solo cultivado com cana-deaçúcar. Planta Daninha, v. 25, n. 1, p. 111-124, 2007. 